Christopher A. Beck, PhD

Denise B. Beran

Kevin M. Biglan, MD, $\mathrm{MPH}$

Cynthia M. Boyd, MD, $\mathrm{MPH}$

E. Ray Dorsey, MD, MBA

Peter N. Schmidt, PhD

Richard Simone, MS

Allison W. Willis, MD, MS

Nicholas B. Galifianakis, $\mathrm{MD}, \mathrm{MPH}$

Maya Katz, MD

Caroline M. Tanner, MD, $\mathrm{PhD}$

Kristen Dodenhoff, BA

Jason Aldred, MD

Julie Carter, RN, MN, ANP

Andrew Fraser, BS, PA-S

Joohi Jimenez-Shahed, MD

Christine Hunter, RN, BSN

Meredith Spindler, MD

Suzanne Reichwein, BASW

Zoltan Mari, MD

Becky Dunlop, RN

John C. Morgan, MD, $\mathrm{PhD}$

Dedi McLane, MS

Patrick Hickey, DO

Lisa Gauger, BA

Irene Hegeman Richard, MD

Nicte I. Mejia, MD, $\mathrm{MPH}$

Grace Bwala, MBBS, $\mathrm{MPH}$

Martha Nance, MD

Ludy C. Shih, MD

Carlos Singer, MD

Author list continued on next page

\section{National randomized controlled trial of virtual house calls for Parkinson disease}

(6)

\section{ABSTRACT}

Objective: To determine whether providing remote neurologic care into the homes of people with Parkinson disease (PD) is feasible, beneficial, and valuable.

Methods: In a 1-year randomized controlled trial, we compared usual care to usual care supplemented by 4 virtual visits via video conferencing from a remote specialist into patients' homes. Primary outcome measures were feasibility, as measured by the proportion who completed at least one virtual visit and the proportion of virtual visits completed on time; and efficacy, as measured by the change in the Parkinson's Disease Questionnaire-39, a quality of life scale. Secondary outcomes included quality of care, caregiver burden, and time and travel savings.

Results: A total of 927 individuals indicated interest, 210 were enrolled, and 195 were randomized. Participants had recently seen a specialist (73\%) and were largely college-educated (73\%) and white (96\%). Ninety-five (98\% of the intervention group) completed at least one virtual visit, and $91 \%$ of 388 virtual visits were completed. Quality of life did not improve in those receiving virtual house calls (0.3 points worse on a 100 -point scale; $95 \%$ confidence interval $[\mathrm{Cl}]-2.0$ to 2.7 points; $p=0.78$ ) nor did quality of care or caregiver burden. Each virtual house call saved patients a median of 88 minutes (95\% Cl 70-120; $p<0.0001)$ and 38 miles per visit (95\% Cl 36-56; $p<0.0001)$.

Conclusions: Providing remote neurologic care directly into the homes of people with PD was feasible and was neither more nor less efficacious than usual in-person care. Virtual house calls generated great interest and provided substantial convenience.

\section{ClinicalTrials.gov identifier: NCT02038959.}

Classification of evidence: This study provides Class III evidence that for patients with PD, virtual house calls from a neurologist are feasible and do not significantly change quality of life compared to in-person visits. The study is rated Class III because it was not possible to mask patients to visit type. Neurology ${ }^{\circledR}$ 2017;89:1152-1161

\section{GLOSSARY}

$\mathbf{C l}$ = confidence interval; PD = Parkinson disease; PDQ-39 = Parkinson's Disease Questionnaire-39.

Telehealth's promise and prevalence are increasing despite its limited evidence base. ${ }^{1}$ In 2001, the Institute of Medicine stated "The Internet has enormous potential to transform health care ... Many of these applications are currently within reach, including remote consultations in the home." ${ }^{2}$ The "virtual house call"3 is now emerging to bring care to patients rather than patients to care.

From the Department of Biostatistics and Computational Biology (C.A.B.), University of Rochester, NY; National Parkinson Foundation (D.B.B., P.N.S.), Miami, FL; Department of Neurology (K.M.B., E.R.D., I.H.R., H.S.) and The Center for Human Experimental Therapeutics (E.R.D., M.A.A., M.J.E., S.G., H.T.K., R.K., S.S., E.A.S., W.Z.), University of Rochester Medical Center, NY; Division of Geriatric Medicine and Gerontology, Department of Medicine (C.M.B., Z.M., B.D.), Johns Hopkins University School of Medicine, Baltimore, MD; Simone Consulting (R.S.), Sunnyvale, CA; Departments of Neurology and Biostatistics and Epidemiology (A.W.W., M.S., S.R.), University of Pennsylvania Perelman School of Medicine, Philadelphia; University of California San Francisco (N.B.G., M.K., C.M.T., K.D.); Northwest Neurological, PLLC

(J. Aldred), Spokane, WA; Oregon Health and Science University (J.C., A. Fraser), Portland; Baylor College of Medicine (J.J.-S., C.H.), Houston, TX; Augusta University (J.C.M., D.M.), GA; Duke Medical Center (P.H., L.G.), Durham, NC; Massachusetts General Hospital (N.I.M., G.B.), Boston; Struthers Parkinson's Center (M.N.), Minneapolis, MN; Beth Israel Deaconess Medical Center (L.C.S.), Boston, MA; University of Miami (C.S., S.V.-P.), FL; Northwestern University (C.Z., N.O.), Evanston, IL; The Feinstein Institute for Medical Research (A. Feigin, J. Ayan), Northwell Health, Manhasset, NY; Medical University of South Carolina (C.V.), Charleston; University of Kansas Medical Center (R.P.), Kansas City; Parkinson's Institute (R.D.), Sunnyvale, CA; Mayo Clinic (A.H.), Rochester, MN; Center for Information Technology Research in the Interest of Society (CITRIS) (S.D.), University of California, Berkeley; Health Informatics Centre (S.S.R.), Karolinska Institute, Stockholm, Sweden; and PatientsLikeMe (P.W.), Derby, UK.

Coinvestigators are listed at Neurology.org.

Go to Neurology.org for full disclosures. Funding information and disclosures deemed relevant by the authors, if any, are provided at the end of the article. 
Silvia Vargas-Parra, MD,

CRC

Cindy Zadikoff, MD

Natalia Okon, BS

Andrew Feigin, MD

Jean Ayan, RN

Christina Vaughan, MD, MHS

Rajesh Pahwa, MD

Rohit Dhall, MD, MSPH

Anhar Hassan, MB, BCh

Steven DeMello, MBA

Sara S. Riggare, MSc

Paul Wicks, PhD

Meredith A. Achey, BM

Molly J. Elson, BA

Steven Goldenthal, BS

H. Tait Keenan, BA

Ryan Korn, BA

Heidi Schwarz, MD

Saloni Sharma, MD

E. Anna Stevenson, MS

William Zhu, BA

On behalf of the

Connect.Parkinson

Investigators

Correspondence to

Dr. Dorsey:

ray.dorsey@chet.rochester.edu

Editorial, page 1103

Supplemental data at Neurology.org
While virtual house calls are increasingly common for episodic conditions, ${ }^{4,5}$ limited evidence supports their application to chronic conditions. A literature review of 141 studies of telehealth for chronic conditions $s^{6}$ identified just 16 that evaluated video conferencing between physician and patient. Only 6almost all single-center, short, and smallevaluated physicians video conferencing directly into patients' homes. ${ }^{7}$

Parkinson disease (PD) is an archetypal chronic condition that increases in incidence with age, ${ }^{8}$ progressively disables those affected, impairs driving ability, ${ }^{9}$ burdens caregivers, ${ }^{7}$ increases health care costs, and benefits from specialized care. ${ }^{10-13}$ However, over $40 \%$ of people with PD never receive care from a neurologist. These people are more likely to have increased morbidity, loss of independence, and premature mortality. ${ }^{11,12,14}$

Pilot efforts have suggested that virtual house calls are feasible, valuable to patients, and have similar clinical outcomes to inperson care in PD. ${ }^{15-19}$ We therefore conducted a national randomized controlled study of virtual house calls to determine whether this model of specialty care delivery is feasible, valuable, and beneficial.

METHODS Trial design. As previously described, ${ }^{7,20}$ we conducted a 12-month randomized controlled trial investigating whether providing remote neurologic care into the homes of people with PD is feasible, beneficial, and valuable (Level III evidence). We compared usual care provided by local physicians to usual care augmented by 4 virtual visits from a remote neurologist. Individuals were randomized 1:1 to either receive virtual visits from a specialist located at one of 18 sites or continue their usual care. The study's biostatistician (C.A.B.) generated the randomization allocation sequence using $\mathrm{R}$ version 3.0.2. Randomization was concealed from sites, stratified by enrolling site, contained a block size of 4 , and occurred after a baseline visit with a blinded rater. After randomization, neither participants nor site investigators were masked to treatment assignment.

The study evaluated (1) the feasibility of virtual house calls; (2) their effect on quality of life; (3) their effect on quality of care; and (4) their ability to save time, reduce caregiver burden, and cut travel. ${ }^{20}$

This study is listed on ClinicalTrials.gov (NCT02038959).

Study participants. Eligible participants had a clinical diagnosis of PD; had a private, Internet-enabled device; and lived in a state where a site investigator was licensed to practice. Individuals who were currently hospitalized, had a condition (e.g., prominent psychosis) that would preclude study participation in the judgment of the site investigator, or were currently enrolled in another telemedicine study were excluded from the study. Participants' caregivers were also invited to participate.

Study procedures. All study activities were conducted remotely. The National Parkinson Foundation, PatientsLikeMe (a patient social networking site), and Michael J. Fox Foundation's Fox Trial Finder's electronic outreach comprised the primary recruitment method. The National Parkinson Foundation also hosted a national helpline for study-related information. ${ }^{20}$

Interested individuals were pointed to a 1-page website where they could reach out to the coordinating center through an online form. The coordinating center directed these individuals to an appropriate site. Site coordinators then sent eligible individuals a consent form and reviewed it with them by phone. Upon enrolling, participants were sent an e-mail link to Health Insurance Portability and Accountability Act-compliant video conferencing software developed by SBR Health (Cambridge, MA), which downloads video conferencing software from Vidyo (Hackensack, $\mathrm{NJ}$ ) and is hosted by ID Solutions (Indianapolis, IN). ${ }^{20}$ Participants who did not have a web-enabled camera were mailed one (Creative Labs Live! Cam Chat HD camera; Creative Technology, Ltd., Singapore). ${ }^{20}$ Technological support was provided by study coordinators by phone.

Intervention. Individuals randomized to the intervention received up to 4 virtual visits over 12 months from a neurologist. The patient and physician determined the specific content and frequency of each visit, but the format generally included a medical history; a PD-specific examination, including assessment of tremor and gait $^{15}$; time to address patients' concerns; and recommendations. Due to differences in state laws governing the remote prescription of medication, ${ }^{21}$ recommendations were mailed to the patient and his or her usual clinician. Individuals randomized to the control group had the option to receive one virtual visit after the study's conclusion. ${ }^{20}$

Outcomes. Feasibility, as defined by the proportion of people who completed at least one virtual visit and the proportion of virtual visits completed as scheduled; and efficacy, as defined by the 12-month change in the Parkinson's Disease Questionnaire-39 (PDQ-39), comprised the primary outcomes. ${ }^{20}$

Quality of care, as quantified by 12-month change in the Patient Assessment of Chronic Illness Care, time and travel savings, and 12-month change in caregiver burden as quantified by the Multidimensional Caregiver Strain Index, comprised the secondary outcomes. ${ }^{20}$

Additional secondary outcomes included the 12-month change in the Movement Disorder Society-sponsored revision of the Unified Parkinson's Disease Rating Scale ${ }^{22}$ score as assessed by the independent rater. The motor portion (part III) of the scale was modified to exclude assessments of rigidity and balance, which cannot be assessed remotely. ${ }^{23}$ Additional assessments included changes in the 15-item Geriatric Depression Scale, the Montreal Cognitive Assessment, the European Quality of Life Five Dimension Five Level Scale, and the Patient Global Impression of Change. Patient and clinician satisfaction, as well as hospitalizations and emergency department visits, were evaluated by survey after each visit. The relative preference for virtual visits vs in-person care was assessed after the last virtual visit. Deaths, breaches of confidentiality, and safety concerns were reported by study sites to the study's principal investigator.

Statistical analysis. Primary measures of feasibility were summarized using descriptive statistics. Virtual house calls were considered feasible if $80 \%$ of participants in the intervention 
arm completed at least one visit and if at least $80 \%$ of virtual visits were completed as scheduled. For the primary efficacy measure, we used an intention-to-treat analysis and fit an analysis of covariance model with the 12-month change in the PDQ-39 as the response, treatment group as the factor of interest, participating specialist as a stratification factor, and baseline score as a covariate. A $t$ test was performed to compare the adjusted treatment group means. ${ }^{7}$ The interaction between treatment group and baseline score was also tested for significance. The robustness of the analysis to model assumptions was assessed using residual diagnostics and remedial measures. Sensitivity of the analysis to the exclusion of missing data was evaluated by imputing missing data using Multiple Imputation by Chained Equations. ${ }^{24}$ Missing individual items on the PDQ-39 were imputed based on the nonmissing items at both baseline and 12 months using predictive mean matching. Secondary measures of quality of life, clinical benefit, quality of care, and value to patients and care partners were analyzed similarly. ${ }^{7}$ Baseline characteristics were compared between treatment groups using Fisher exact test for nominal data and the exact Wilcoxon rank-sum test for ordinal and continuous data. Measures of value, satisfaction, and global impression of change were analyzed similarly. All statistical tests were performed with a 2-sided significance level of $5 \%$, and no correction was made for multiple comparisons.

Sample size. A sample size of 200 participants was selected to ensure adequate power $(80 \%-90 \%)$ to detect a modest effect size on the PDQ-39 (Cohen $d$ of 0.5 ) using a 2 -sided $t$ test at a significance level of $5 \%$ and allowing for anticipated dropout rate of up to $20 \%$.

Standard protocol approvals, registrations, and patient consents. The institutional review boards of the University of Rochester (coordinating center) and the sites approved the study. All participants provided written informed consent.

Figure $1 \quad$ Flowchart of study participants

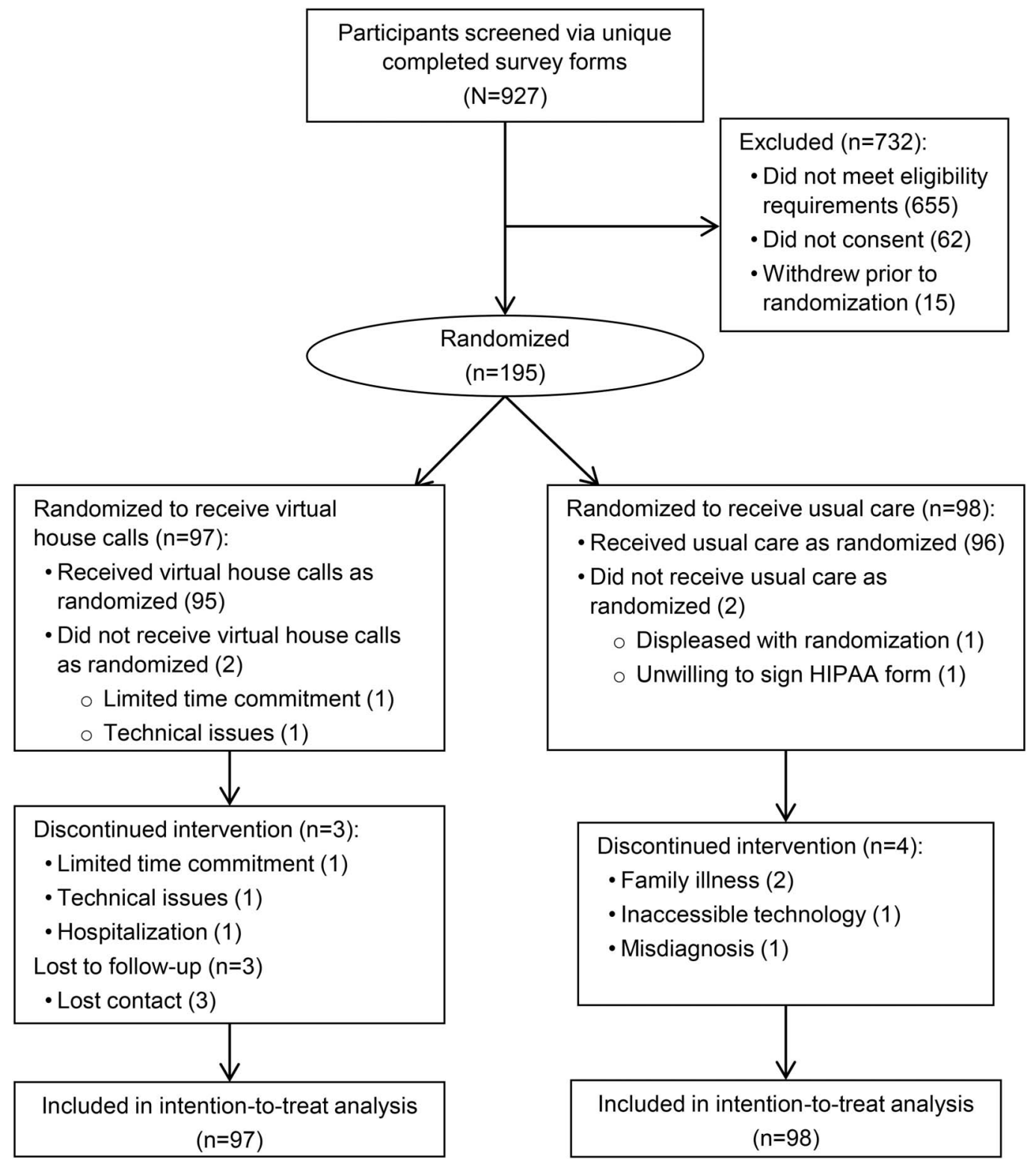

HIPAA $=$ Health Insurance Portability and Accountability Act. 


\begin{tabular}{|c|c|c|c|}
\hline & $\begin{array}{l}\text { All randomized } \\
\text { participants } \\
\text { (n = 195) }\end{array}$ & $\begin{array}{l}\text { Virtual house } \\
\text { calls }(n=97)\end{array}$ & $\begin{array}{l}\text { Usual care } \\
(\mathrm{n}=98)\end{array}$ \\
\hline \multicolumn{4}{|l|}{ Demographics } \\
\hline Women, n (\%) & $91(46.7)$ & $49(50.5)$ & $42(42.8)$ \\
\hline \multicolumn{4}{|l|}{ Race, n (\%) } \\
\hline Other & $3(1.5)$ & $3(3.1)$ & $0(0)$ \\
\hline Did not answer/unknown & 5 (2.6) & $2(2.1)$ & $3(3.1)$ \\
\hline \multicolumn{4}{|l|}{ Ethnicity, n (\%) } \\
\hline Hispanic/Latino & $3(1.5)$ & $1(1.0)$ & $2(2.0)$ \\
\hline Presently married, n (\%) & $151(77.4)$ & 75 (77.3) & 76 (77.6) \\
\hline \multicolumn{4}{|l|}{ Participants with care partners, relationship to participant, $\mathrm{n}(\%)$} \\
\hline Spouse/partner & $132(67.7)$ & $63(65.0)$ & $69(70.4)$ \\
\hline No response/no care partner & $54(27.7)$ & $29(29.9)$ & 35 (35.5) \\
\hline Child/grandchild & 7 (3.6) & $3(3.1)$ & $4(4.1)$ \\
\hline Other & $2(1.0)$ & $2(2.1)$ & $0(0)$ \\
\hline \multicolumn{4}{|l|}{ Internet use and familiarity, $\mathrm{n}(\%)$} \\
\hline Participants who use the Internet or e-mail at home & 187 (95.9) & 95 (97.9) & 92 (93.9) \\
\hline MDS-UPDRS, part 1B (0-28) & $10.3(4.4)$ & $10.7(4.5)$ & $10.0(4.4)$ \\
\hline MDS-UPDRS, part $2(n=194)(0-52)^{a}$ & $14.7(7.6)$ & $15.4(8.5)$ & $14.1(6.7)$ \\
\hline Modified MDS-UPDRS, part $3(0-108)^{a, b}$ & $28.9(10.0)$ & $29.5(10.2)$ & $28.3(9.9)$ \\
\hline MDS-UPDRS, part $4(n=194)(0-24)^{a}$ & $4.5(4.8)$ & $4.7(4.9)$ & $4.2(4.7)$ \\
\hline Montreal Cognitive Assessment score $(0-30)^{c}$ & $26.2(2.8)$ & $26.1(2.7)$ & $26.4(2.9)$ \\
\hline Parkinson's Disease Questionnaire-39 total score $(n=177)(0-100)^{a}$ & $25.4(13.9)$ & $26.3(15.2)$ & $24.6(12.6)$ \\
\hline EuroQol 5D $(0-1)^{c}$ & $0.8(0.1)$ & $0.8(0.1)$ & $0.8(0.1)$ \\
\hline Geriatric Depression Scale-15 $(n=190)(0-15)^{a}$ & $4.1(3.2)$ & $4.1(3.2)$ & 4.1 (3.2) \\
\hline Patient Assessment of Chronic Illness Care Composite Score $(n=182)(1-5)^{c}$ & $2.4(0.9)$ & $2.4(0.9)$ & $2.4(0.9)$ \\
\hline \multicolumn{4}{|l|}{ Parkinson disease care } \\
\hline Participants who have seen a general neurologist for Parkinson disease in the last 12 months, $n(\%)$ & $85(43.6)$ & $48(49.5)$ & $37(37.7)$ \\
\hline Participants who have seen a Parkinson disease specialist in the last 12 months, $n(\%)$ & $143(73.3)$ & $64(66.0)$ & 79 (80.6) \\
\hline Participants who are satisfied or very satisfied with their current Parkinson disease care, $n(\%)$ & $143(73.3)$ & $67(69)$ & $76(77.5)$ \\
\hline Number of emergency room visits in the last 12 months $(n=194)$ & $0.66(1.95)$ & $0.84(2.47)$ & $0.48(1.23)$ \\
\hline Number of times admitted to the hospital overnight in the last 12 months & $0.23(0.62)$ & $0.24(0.67)$ & $0.21(0.56)$ \\
\hline
\end{tabular}

Abbreviation: MDS-UPDRS = Movement Disorder Society-sponsored revision of the Unified Parkinson's Disease Rating Scale.

All values are mean (SD) unless otherwise noted. The number of responses is 195 unless otherwise noted.

${ }^{a}$ Higher scores indicate greater disability.

${ }^{b}$ Excludes rigidity and postural stability assessments, which cannot be performed remotely.

${ }^{c}$ Lower scores indicate greater disability/dissatisfaction. 
RESULTS Study population. A total of 11,734 individuals from all 50 states and 80 countries visited the study's website over 6 months of recruitment. A total of $1,704(15 \%)$ continued to the online interest form, and 927 (8\%) completed it (figure 1). ${ }^{20}$ Outreach efforts through the National Parkinson Foundation reached the most people $(\mathrm{n}=339)$, followed by PatientsLikeMe $(\mathrm{n}=204)$ and Fox Trial Finder $(\mathrm{n}=132) .{ }^{20}$ A total of 272 individuals were directed to enrolling sites, 210 were enrolled, and 195 were randomized. ${ }^{20}$ Study participants were mostly white (96\%), college-educated (73\%), and on average 66 years old. Fifteen participants withdrew before randomization, primarily due to technical reasons (e.g., incompatible computer) and losses to follow-up (figure 1). ${ }^{20}$ Participants who withdrew had similar baseline characteristics to participants who were randomized. Participants were familiar with the Internet and e-mail (96\%) and half had previously conducted a video call. Baseline access $(73 \%$ had seen a PD specialist in the prior year) and satisfaction with care (83\% satisfied or very satisfied) were very high (table 1 ). Most participating caregivers were also white (79\%) and college-educated (56\%) (table e-1 at Neurology.org). ${ }^{20}$

Primary outcome measures. Ninety-five (98\%) of the 97 individuals randomized to the intervention arm completed at least one virtual visit, and $91 \%$ of the
388 virtual visits were completed as scheduled. Excluding one outlier (277 visits) in the intervention group, the number of visits to the local clinician was similar between the 2 groups (2.5 in-person visits in the virtual visit group and 3.0 in-person visits in the usual care group; $p=0.14$ ). As shown in table 2 , the change in quality in life as measured by the PDQ-39 did not differ between the 2 groups ( 0.3 points worse on a 100 -point scale; $95 \%$ confidence interval [CI] -2.0 to 2.7 points; $p=0.78$ ).

Secondary outcomes. Patient assessment of quality of care improved from baseline by 0.3 points $(95 \% \mathrm{CI}$ $0.1-0.5 ; p=0.01)$ in those randomized to virtual visits and 0.3 points (95\% CI $0.1-0.4 ; p=0.02)$ in those randomized to usual care, and the change did not differ between the 2 groups. Compared to usual in-person care, virtual visits saved patients time (median of 88 minutes per visit [95\% CI 70-120; $p<0.0001]$ ) and travel (median of 38 miles round-trip per visit [95\% CI 36-56; $p<0.0001]$ ). The change in caregiver burden did not differ between groups (table 2).

Additional clinical outcomes. The change in clinical outcomes did not differ between the 2 groups (table 2). However, as shown in figure e-1, the patient global impression of change as rated by the study participants was better in those randomized to receive virtual house calls $(50 \%$ vs $32 \%$

Table 2 Primary and secondary outcomes

\begin{tabular}{|c|c|c|c|c|}
\hline Measure & $\begin{array}{l}\text { Mean change in } \\
\text { virtual house call } \\
\text { group }(95 \% \mathrm{Cl})\end{array}$ & $\begin{array}{l}\text { Mean change in } \\
\text { usual care group } \\
(95 \% \mathrm{Cl})\end{array}$ & $\begin{array}{l}\text { Mean difference } \\
\text { between groups } \\
(95 \% \mathrm{Cl})\end{array}$ & p Value \\
\hline \multicolumn{5}{|l|}{ Primary outcome measure } \\
\hline Parkinson's Disease Questionnaire-39 $(n=160)$ & $-0.4(-2.4$ to 1.6$)$ & $-0.8(-2.6$ to 1.1$)$ & $0.3(-2.0$ to 2.7$)$ & 0.78 \\
\hline \multicolumn{5}{|l|}{ Secondary outcome measures } \\
\hline $\begin{array}{l}\text { Patient Assessment of Chronic Illness Care } \\
(n=167)\end{array}$ & $0.3(0.1$ to 0.5$)$ & $0.3(0.1$ to 0.4$)$ & $0.0(-0.2$ to 0.3$)$ & 0.79 \\
\hline Caregiver Strain Index $(n=51)$ & $0.3(-3.0$ to 3.6$)$ & $0.5(-2.2$ to 3.3$)$ & $-0.2(-4.4$ to 3.9$)$ & 0.90 \\
\hline MDS-UPDRS, part IA ( $\mathrm{n}=181)$ & $-0.8(-1.4$ to -0.2$)$ & $-1.0(-1.6$ to -0.4$)$ & $0.2(-0.6$ to 0.9$)$ & 0.68 \\
\hline MDS-UPDRS, part IB (n = 177) & $0.1(-0.6$ to 0.9$)$ & 0.4 (1.1 to 0.3$)$ & $-0.3(-1.2$ to 0.7$)$ & 0.57 \\
\hline MDS-UPDRS, part II (n = 176) & 0.1 ( -0.8 to 1.1$)$ & $-0.3(-1.3$ to 0.7$)$ & 0.5 ( -0.8 to 1.7$)$ & 0.46 \\
\hline Modified MDS-UPDRS, part III (n = 177) & $-5.7(-7.7$ to -3.7$)$ & $-4.9(-6.8$ to -3.0$)$ & $-0.8(-3.3$ to 1.6$)$ & 0.51 \\
\hline Modified MDS-UPDRS, part IV ( $n=180)$ & $-0.2(-1.0$ to 0.7$)$ & $-0.2(-1.0$ to 0.6$)$ & $0.0(-1.0$ to 1.1$)$ & 0.96 \\
\hline Geriatric Depression Scale $(n=175)$ & $0.2(-0.4$ to 0.7$)$ & $-0.0(-0.5$ to 0.5$)$ & $0.2(-0.5$ to 0.8$)$ & 0.62 \\
\hline Montreal Cognitive Assessment $(n=180)$ & 0.6 (0.1 to 1.2$)$ & $0.2(-0.3$ to 0.7$)$ & $0.4(-0.2$ to 1.1$)$ & 0.16 \\
\hline EuroQol 5D ( $n=180)$ & $0.0(-0.1$ to 0.0$)$ & $0.0(-0.1$ to 0.0$)$ & $0.0(0.0$ to 0.0$)$ & 0.32 \\
\hline $\begin{array}{l}\text { Number of emergency room visits in the last } \\
12 \text { months }(n=181)\end{array}$ & $0.5(0.4$ to 0.7$)$ & 0.7 (0.3 to 1.0$)$ & 0.1 ( -0.3 to 0.5$)$ & 0.38 \\
\hline $\begin{array}{l}\text { Number of times admitted to the hospital } \\
\text { overnight }(n=181)\end{array}$ & 0.2 (0.1 to 0.3$)$ & $0.3(0.2$ to 0.4$)$ & 0.1 ( -0.1 to 0.2$)$ & 0.32 \\
\hline
\end{tabular}

Abbreviations: $\mathrm{Cl}$ = confidence interval; MDS-UPDRS = Movement Disorder Society-sponsored revision of the Unified Parkinson's Disease Rating Scale. 


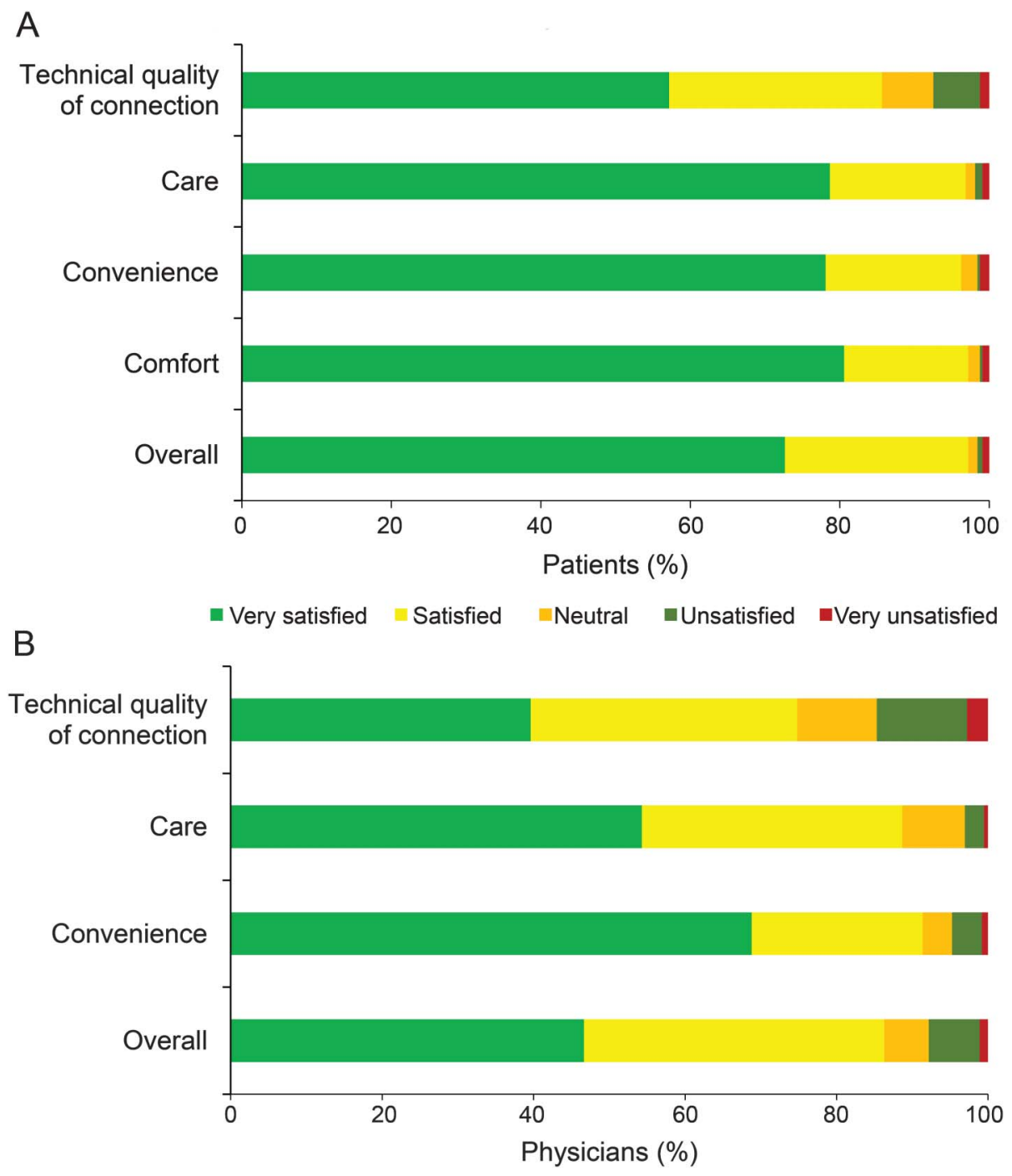

(A) Patient satisfaction with virtual house calls $(\mathrm{n}=320)$. (B) Physician satisfaction with virtual house calls $(\mathrm{n}=361)$.

randomized to the control group reported feeling at least "a little better"; $p=0.002$ ). The frequency of hospital visits or emergency room use did not change.

On average, data were missing for $10 \%$ of all participants (range 7\%-19\%) and did not differ by group. In most cases, missing items were 1-2 responses to the PDQ-39. Sensitivity analyses assessing the effect of missing data and deviations from the underlying model assumptions were consistent with the analyses presented in table 2.

Patient and physician satisfaction. As shown in figure 2, $97 \%$ of patients and $86 \%$ of physicians were satisfied or very satisfied with virtual visits.

Patient preference. At the study's end, participants preferred virtual visits with their remote specialist to their usual in-person PD clinician on all aspects measured (figure 3). Overall, participants preferred virtual visits over in-person visits. $(55 \%$ vs $18 \%$; $p<0.0001)$.
Safety. No deaths, harm (e.g., privacy breaches), or safety issues (e.g., falls during remote examination) were identified during the course of the study.

DISCUSSION As demonstrated in this national study, providing remote neurologic care to individuals with PD directly into their homes is feasible. The proportion of visits completed (over 90\%) is in line with the proportion of in-person clinic visits completed in an earlier pilot study ${ }^{16}$ and on par with, if not better than, many published studies of no-show rates for traditional in-person clinic appointments. ${ }^{25}$

The absence of improvement in quality of life from the addition of virtual visits in this study could be due to several factors, including the possibility that virtual visits with a specialist are insufficient to improve quality of life. Additional possibilities include the very high proportion of individuals who were already receiving care from a PD specialist at 
Figure 3 Participants' relative preference of virtual house calls with remote specialist vs in-person visit with usual Parkinson disease provider across different dimensions $(n=68)$

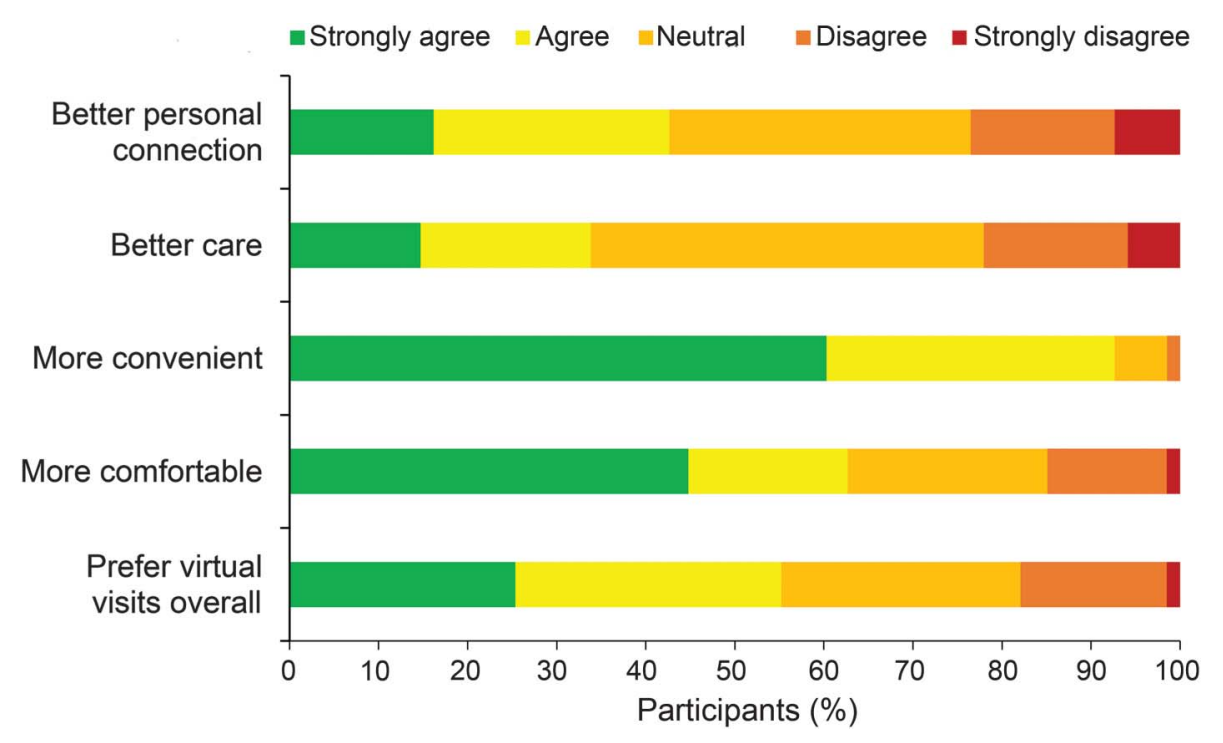

baseline, the high satisfaction with that care at baseline, the required reliance (due to state licensing laws) on local clinicians to implement the specialist's recommendations, and the choice of measure used (the patients' global impression of change was significantly favorable for those receiving virtual visits).

Beyond the primary efficacy outcome measure, ${ }^{26}$ the secondary outcomes highlight the care model's benefits and are consistent with most of the Institute of Medicine's recommendations for improving care. $^{2}$ In addition to their likely comparable efficacy to in-person care, virtual house calls save timea median of 88 minutes and an average of $169 \mathrm{mi}$ nutes of time per visit. In addition, virtual house calls are efficient and eliminated approximately 35,000 miles of travel and reduce the need for parking lots, waiting rooms, and clinic space. Virtual house calls are also safe, with no safety issues arising during the study, and are patient-centered. The visits provide most patients the care that they prefer, the convenience that they need, and the comfort that they value. ${ }^{18}$

However, like current care ${ }^{12,27}$ and many clinical trials, ${ }^{28}$ study participation was not equitable. Fueled by online recruitment, the study participants reflected the digital divide, the differential access to the Internet and related technologies due to social and geographic factors. ${ }^{29}$ While the study enrolled participants as old as 84 years of age and over half came from counties with limited access to neurologic care, study participants were largely white, welleducated, and more familiar with the Internet than the general population. ${ }^{30}$ The study results thus may not be generalizable to the broader community of individuals with PD.

Additional limitations included the target population, intervention, availability of data, and scope of analysis. First, this study excluded individuals with PD who reside in nursing homes, who account for nearly $25 \%$ of all Medicare beneficiaries with $\mathrm{PD},{ }^{13}$ frequently have limited access to neurologic care, ${ }^{15}$ and benefit from virtual visits. Other underserved populations (e.g., rural) who have less access to care may stand more to benefit. Second, the intervention was limited to care from a neurologist, whereas $\mathrm{PD}$, like many chronic conditions, benefits from multidisciplinary care. ${ }^{31}$ In addition, while studies have generally demonstrated that remote and inperson motor examinations are comparable, ${ }^{15}$ assessing gait remotely can be difficult due to the technology, limited camera view, and absence of trained clinicians. Third, this study had some missing data, which did not appear to affect results, and a lower response rate for some survey questions, which provides the potential for response bias. For example, nonresponders may have rated virtual house calls less favorably than responders, who nonetheless accounted for $70 \%$ of responses. Fourth, this study had limited consideration of costs. Utilization of emergency rooms and hospitalizations was low in both groups before and during the study. One general concern with telehealth is that it will lead to more physician visits, ${ }^{32}$ and those in the intervention group had more total physician visits than those in the control group. However, physician visits are inexpensive relative to institutional care, and more frequent visits to a neurologist for PD are associated with fewer hospitalizations and lower overall health expenditures. ${ }^{13}$ 
Future efforts can address these study limitations. Dedicated outreach to underserved populations, including those with advanced disease and from underserved demographic groups, especially women, rural residents, minorities, homebound, or those in assisted living facilities, will help determine if the results are more generalizable and whether the benefits are potentially greater for those with historically less access to care. Incorporation of multidisciplinary care to address comorbid conditions (e.g., depression) could provide additional value when remotely brought into the home or in combination with traditional clinic appointments and in-person home visits. Future studies could also include rigorous economic assessments, perhaps by focusing on individuals with high current costs or those at risk for hip fractures, psychosis, or nursing home placement. Such assessments should include the economic benefits to patients and caregivers, which are frequently discounted. ${ }^{33}$ Finally, the generalizability of these results can be assessed through investigations in other conditions associated with aging (e.g., Alzheimer disease), ${ }^{11}$ reduced mobility (e.g., amyotrophic lateral sclerosis), or limited specialty access (e.g., Duchenne muscular dystrophy). ${ }^{34}$

This study also provides guidance to address policy barriers that prevent broader implementation of telehealth. ${ }^{1}$ One large barrier is Medicare's sparse coverage of telehealth, which in 2015 amounted to less than $0.01 \%$ of its budget. ${ }^{35}$ Extending Medicare's telehealth coverage to the home and to all beneficiaries regardless of geography would mirror other federal (e.g., Veterans' Administration) ${ }^{36}$ and private (e.g., Kaiser Permanente of Northern California) ${ }^{37}$ payers. Another policy barrier is that patients can only receive care from physicians licensed in their state. Interest in this study was immense nationally, and the primary reason individuals could not participate was their location in a state where none of the participating physicians was licensed. Policies, such as the Tele-MED Act, ${ }^{38}$ which would enable any Medicare beneficiaries to receive care from any licensed Medicare provider, or timely and efficient implementation of the Interstate Medical Licensure Compact, ${ }^{39}$ which would facilitate licensure of physicians in multiple states, could help address this barrier. Finally, some states require that any care provided via telehealth be preceded by in-person care, ${ }^{21}$ but in this study almost all participants were seen remotely by specialists they had never physically met without incident and with great satisfaction. Where these barriers are not present, either outside the United States (e.g., Canada) or inside the United States (e.g., Veterans' Administration), telehealth is flourishing.

This study funded by the Patient-Centered Outcomes Research Institute rigorously evaluates an important and growing model of care. The remote delivery of specialty care to individuals with $\mathrm{PD}$ directly in their homes is feasible, and while their addition did not improve (or hinder) quality of life in this study, their convenience and comfort warrant further investigation and implementation. Virtual house calls address the Institute of Medicine's vision for high-quality health care and were found to be timely, efficient, and patient-centered. Future efforts must address the digital divide and policy barriers to ensure that this new care model can address inequities in access to care.

\section{AUTHOR CONTRIBUTIONS}

Christopher A. Beck: analysis or interpretation of data, design or conceptualization of the study, drafting or revising the manuscript for intellectual content. Denise B. Beran: analysis or interpretation of data, design or conceptualization of the study, drafting or revising the manuscript for intellectual content. Kevin M. Biglan: analysis or interpretation of data, design or conceptualization of the study, drafting or revising the manuscript for intellectual content. Cynthia M. Boyd: analysis or interpretation of data, design or conceptualization of the study, drafting or revising the manuscript for intellectual content. E. Ray Dorsey: analysis or interpretation of data, design or conceptualization of the study, drafting or revising the manuscript for intellectual content. Peter N. Schmidt: analysis or interpretation of data, design or conceptualization of the study, drafting or revising the manuscript for intellectual content. Richard Simone: analysis or interpretation of data, design or conceptualization of the study, drafting or revising the manuscript for intellectual content. Allison W. Willis: analysis or interpretation of data, design or conceptualization of the study, drafting or revising the manuscript for intellectual content. Nicholas B. Galifianakis: analysis or interpretation of data, drafting or revising the manuscript for intellectual content. Maya Katz: analysis or interpretation of data, drafting or revising the manuscript for intellectual content. Caroline M. Tanner: analysis or interpretation of data, drafting or revising the manuscript for intellectual content. Kristen Dodenhoff: analysis or interpretation of data, drafting or revising the manuscript for intellectual content. Jason Aldred: analysis or interpretation of data, drafting or revising the manuscript for intellectual content. Julie Carter: analysis or interpretation of data, drafting or revising the manuscript for intellectual content. Andrew Fraser: analysis or interpretation of data, drafting or revising the manuscript for intellectual content. Joohi Jiminez-Shahed: analysis or interpretation of data, drafting or revising the manuscript for intellectual content. Christine Hunter: analysis or interpretation of data, drafting or revising the manuscript for intellectual content. Meredith Spindler: analysis or interpretation of data, drafting or revising the manuscript for intellectual content. Suzanne Reichwein: analysis or interpretation of data, drafting or revising the manuscript for intellectual content. Zoltan Mari: analysis or interpretation of data, drafting or revising the manuscript for intellectual content. Becky Dunlop: analysis or interpretation of data, drafting or revising the manuscript for intellectual content. John C. Morgan: analysis or interpretation of data, drafting or revising the manuscript for intellectual content. Dedi McLane: analysis or interpretation of data, drafting or revising the manuscript for intellectual content. Patrick Hickey: analysis or interpretation of data, drafting or revising the manuscript for intellectual content. Lisa Gauger: analysis or interpretation of data, drafting or revising the manuscript for intellectual content. Irene Hegeman Richard: analysis or interpretation of data, drafting or revising the manuscript for intellectual content. Nicte I. Mejia: analysis or interpretation of data, drafting or revising the manuscript for intellectual content. Grace Bwala: analysis or interpretation of data, drafting or revising the manuscript for intellectual content. Martha Nance: analysis or interpretation of data, drafting or revising the manuscript for intellectual content. Ludy C. Shih: analysis or interpretation of data, drafting or revising the manuscript for intellectual content. Carlos Singer: analysis or interpretation of data, drafting or revising the manuscript for intellectual content. Silvia 
Vargas-Parra: analysis or interpretation of data, drafting or revising the manuscript for intellectual content. Cindy Zadikoff: analysis or interpretation of data, drafting or revising the manuscript for intellectual content. Natalia Okon: analysis or interpretation of data, drafting or revising the manuscript for intellectual content. Andrew Feigin: analysis or interpretation of data, drafting or revising the manuscript for intellectual content. Jean Ayan: analysis or interpretation of data, drafting or revising the manuscript for intellectual content. Christina Vaughan: analysis or interpretation of data, drafting or revising the manuscript for intellectual content. Rajesh Pahwa: analysis or interpretation of data, drafting or revising the manuscript for intellectual content. Rohit Dhall: analysis or interpretation of data, drafting or revising the manuscript for intellectual content. Anhar Hassan: analysis or interpretation of data, drafting or revising the manuscript for intellectual content. Steven DeMello: analysis or interpretation of data, drafting or revising the manuscript for intellectual content. Sara S. Riggare: analysis or interpretation of data, drafting or revising the manuscript for intellectual content. Paul Wicks: analysis or interpretation of data, drafting or revising the manuscript for intellectual content. Meredith A. Achey: analysis or interpretation of data, drafting or revising the manuscript for intellectual content. Molly J. Elson: analysis or interpretation of data, drafting or revising the manuscript for intellectual content. Steven Goldenthal: analysis or interpretation of data, drafting or revising the manuscript for intellectual content. H. Tait Keenan: analysis or interpretation of data, drafting or revising the manuscript for intellectual content. Ryan Korn: analysis or interpretation of data, drafting or revising the manuscript for intellectual content. Heidi Schwarz: analysis or interpretation of data, drafting or revising the manuscript for intellectual content. Saloni Sharma: analysis or interpretation of data, drafting or revising the manuscript for intellectual content. E. Anna Stevenson: analysis or interpretation of data, drafting or revising the manuscript for intellectual content. William Zhu: analysis or interpretation of data, drafting or revising the manuscript for intellectual content. Dr. Dorsey had full access to all the data in the study and takes responsibility for the conduct of the research, integrity of the data, and accuracy of the data analysis.

\section{ACKNOWLEDGMENT}

The authors thank Christopher Herot, Chief Executive Officer of SBR Health, for technical assistance during the course of the study; and Rita Landgraf, Secretary of Health for Delaware, for her assistance and guidance.

\section{STUDY FUNDING}

The study was funded by the Patient-Centered Outcomes Research Institute (AD-12-11-4701). The Patient-Centered Outcomes Research Institute had no role in the design and conduct of the study; collection, management, analysis, or interpretation of the data; or preparation, review, or approval of the manuscript. Software used in the study was provided and supported by SBR Health (Cambridge, MA), Vidyo (Hackensack, NJ), and ID solutions (Indianapolis, IN).

\section{DISCLOSURE}

C. Beck, D. Beran, K. Biglan, and C. Boyd report no disclosures relevant to the manuscript. E. Dorsey serves on the medical advisory board of and has stock options in Grand Rounds. P. Schmidt, R. Simone, A. Willis, N. Galifianakis, M. Katz, C. Tanner, K. Dodenhoff, J. Aldred, J. Carter, A. Fraser, J. Jiminez-Shahed, C. Hunter, M. Spindler, S. Reichwein, Z. Mari, B. Dunlop, J. Morgan, D. McLane, P. Hickey, L. Gauger, I. Richard, N. Mejia, G. Bwala, M. Nance, L. Shih, C. Singer, S. Vargas-Parra, C. Zadikoff, N. Okron, A. Feigin, J. Ayan, C. Vaughan, R. Pahwa, R. Dhall, A. Hassan, S. DeMello, S. Riggare, P. Wicks, M. Achey, M. Elson, S. Goldenthal, H. Keenan, R. Korn, H. Schwarz, S. Sharma, E. Stevenson, and W. Zhu report no disclosures relevant to the manuscript. Go to Neurology.org for full disclosures.

Received January 12, 2017. Accepted in final form June 1, 2017.

\section{REFERENCES}

1. Dorsey ER, Topol EJ. State of telehealth. N Engl J Med 2016;375:154-161.
2. Crossing the Quality Chasm: A New Health System for the 21st Century. Washington, DC: National Academies Press; 2001.

3. Daschle T, Dorsey ER. The return of the house call. Ann Intern Med 2015;162:587-588.

4. Uscher-Pines L, Mehrotra A. Analysis of teladoc use seems to indicate expanded access to care for patients without prior connection to a provider. Health Aff 2014;33:258-264.

5. Wechsler LR. Advantages and limitations of teleneurology. JAMA Neurol 2015;72:349-354.

6. Wootton R. Twenty years of telemedicine in chronic disease management: an evidence synthesis. J Telemed Telecare 2012;18:211-220.

7. Achey MA, Beck CA, Beran DB, et al. Virtual house calls for Parkinson disease (Connect.Parkinson): study protocol for a randomized, controlled trial. Trials 2014;15:465.

8. Van Den Eeden SK, Tanner CM, Bernstein AL, et al. Incidence of Parkinson's disease: variation by age, gender, and race/ethnicity. Am J Epidemiol 2003;157:1015-1022.

9. Dubinsky RM, Gray C, Husted D, et al. Driving in Parkinson's disease. Neurology 1991;41:517-520.

10. Cheng EM, Swarztrauber K, Siderowf AD, et al. Association of specialist involvement and quality of care for Parkinson's disease. Mov Disord 2007;22:515-522.

11. Dorsey ER, George BP, Leff B, Willis AW. The coming crisis: obtaining care for the growing burden of neurodegenerative conditions. Neurology 2013;80:1989-1996.

12. Willis AW, Schootman M, Evanoff BA, Perlmutter JS, Racette BA. Neurologist care in Parkinson disease: a utilization, outcomes, and survival study. Neurology 2011;77:851-857.

13. Willis AW, Schootman M, Tran R, et al. Neurologistassociated reduction in PD-related hospitalizations and health care expenditures. Neurology 2012;79:1774-1780.

14. Dorsey ER. Testimony to the Subcommittee on Commerce, Manufacturing, and Trade. Available at: http:// docs.house.gov/meetings/IF/IF17/20160713/105197/ HHRG-114-IF17-Wstate-DorseyE-20160713.pdf. Accessed August 2, 2017

15. Dorsey ER, Deuel LM, Voss TS, et al. Increasing access to specialty care: a pilot, randomized controlled trial of telemedicine for Parkinson's disease. Mov Disord 2010;25: 1652-1659.

16. Dorsey ER, Venkataraman V, Grana MJ, et al. Randomized controlled clinical trial of "virtual house calls" for Parkinson disease. JAMA Neurol 2013;70:565-570.

17. Achey M, Aldred JL, Aljehani N, et al. The past, present, and future of telemedicine for Parkinson's disease. Mov Disord 2014;29:871-883.

18. Venkataraman V, Donohue SJ, Biglan KM, Wicks P, Dorsey ER. Virtual visits for Parkinson disease: a case series. Neurol Clin Pract 2014;4:146-152.

19. Wilkinson JR, Spindler M, Wood SM, et al. High patient satisfaction with telehealth in Parkinson disease: a randomized controlled study. Neurol Clin Pract 2016;6:241-251.

20. Dorsey ER, Achey MA, Beck CA, et al. National randomized controlled trial of virtual house calls for people with Parkinson's disease: interest and barriers. Telemed J E Health 2016;22:590-598.

21. State Laws and Reimbursement Policies [online]. Available at: cchpca.org/state-laws-and-reimbursement-policies. Accessed September 1, 2016.

22. Goetz CG, Tilley BC, Shaftman SR, et al. Movement Disorder Society-sponsored revision of the Unified 
Parkinson's Disease Rating Scale (MDS-UPDRS): scale presentation and clinimetric testing results. Mov Disord 2008;23:2129-2170.

23. Abdolahi A, Scoglio N, Killoran A, Dorsey ER, Biglan KM. Potential reliability and validity of a modified version of the Unified Parkinson's Disease Rating Scale that could be administered remotely. Parkinsonism Relat Disord 2013;19:218-221.

24. Van Buuren S, Boshuizen HC, Knook DL. Multiple imputation of missing blood pressure covariates in survival analysis. Stat Med 1999;18:681-694.

25. Guzek LM, Gentry SD, Golomb MR. The estimated cost of "no-shows" in an academic pediatric neurology clinic. Pediatr Neurol 2015;52:198-201.

26. Pocock SJ, Stone GW. The primary outcome fails: what next? N Engl J Med 2016;375:861-870.

27. Dahodwala N, Xie M, Noll E, Siderowf A, Mandell DS Treatment disparities in Parkinson's disease. Ann Neurol 2009;66:142-145.

28. Cummings J, Isaacson S, Mills R, et al. Pimavanserin for patients with Parkinson's disease psychosis: a randomised, placebo-controlled phase 3 trial. Lancet 2014;383:533-540.

29. Norris P. Digital Divide: Civic Engagement, Information Poverty, and the Internet Worldwide. New York: Cambridge University Press; 2001.

30. Internet User Demographics. Washington, DC: Pew Research Center; 2014.
31. Post B, van der Eijk M, Munneke M, Bloem BR. Multidisciplinary care for Parkinson's disease: not if, but how! Pract Neurol 2011;11:58-61.

32. Housman L, Williams Z, Ellis P. Congressional Budget Office: Nonpartisan Analysis for the U.S. Congress. Washington, DC: Congressional Budget Office; 2015.

33. Asch DA. The hidden economics of telemedicine. Ann Intern Med 2015;163:801-802.

34. Cialone J, Augustine EF, Newhouse N, Vierhile A, Marshall FJ, Mink JW. Quantitative telemedicine ratings in Batten disease: implications for rare disease research. Neurology 2011;77:1808-1811.

35. Lacktman NL. Medicare Payments for Telehealth Increased 25\% in 2015: What You Need to Know [online]. Available at: healthcarelawtoday.com/2016/03/03/ medicare-payments-for-telehealth-increased-25-in-2015what-you-need-to-know/. Accessed April 7, 2015.

36. mHealthNews. VA poised to Ramp up Telehealth in 2015 [online]. Available at: mobihealthnews.com/news/vapoised-ramp-telehealth-2015. Accessed April 7, 2015.

37. Pearl R. Kaiser Permanente Northern California: current experiences with internet, mobile, and video technologies. Health Aff 2014;33:251-257.

38. H.R.3081-Tele-Med Act of 2015.

39. Interstate Medical Licensure Compact [online]. Available at: licenseportability.org/. Accessed April 7, 2015.

\section{This Week's Neurology ${ }^{\circledR}$ Podcast}

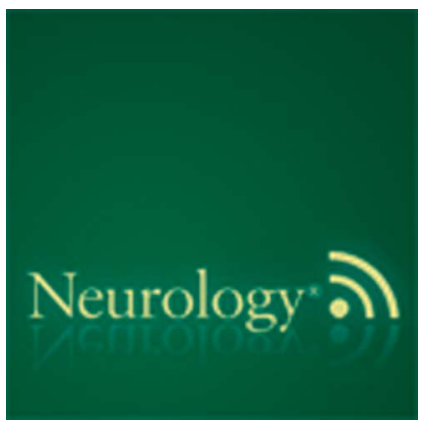

National randomized controlled trial of virtual house calls for Parkinson disease (see p. 1152)

This podcast begins and closes with Dr. Robert Gross, Editor-inChief, briefly discussing highlighted articles from the September 12, 2017, issue of Neurology. In the first segment, Dr. Jeff Ratliff talks with Dr. Ray Dorsey about his paper on virtual house calls for Parkinson disease. In the second part of the podcast, Dr. Andy Southerland interviews Dr. Joseph Safdieh about Dr. Safdieh's new position as Editor-in-Chief of Neurology Today ${ }^{\circledR}$.

Disclosures can be found at Neurology.org.

At Neurology.org, click on "RSS" in the Neurology Podcast box to listen to the most recent podcast and subscribe to the RSS feed.

CME Opportunity: Listen to this week's Neurology Podcast and earn 0.5 AMA PRA Category 1 CME Credits $^{\mathrm{TM}}$ by answering the multiple-choice questions in the online Podcast quiz. 


\section{Neurology}

\section{National randomized controlled trial of virtual house calls for Parkinson disease}

Christopher A. Beck, Denise B. Beran, Kevin M. Biglan, et al.

Neurology 2017;89;1152-1161 Published Online before print August 16, 2017

DOI 10.1212/WNL.0000000000004357

This information is current as of August 16, 2017

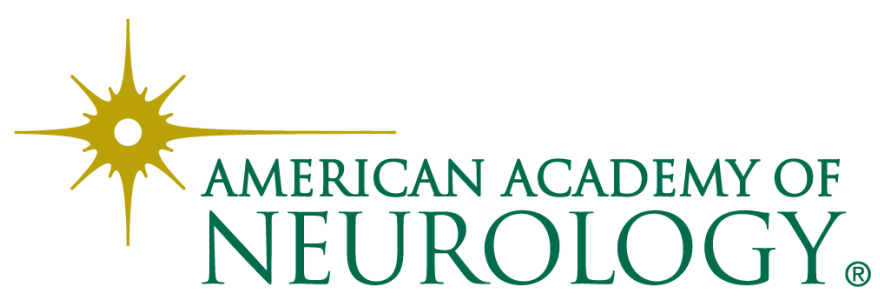




\section{Updated Information \& Services}

\section{Supplementary Material}

\section{References}

Citations

Subspecialty Collections

\section{Permissions \& Licensing}

Reprints including high resolution figures, can be found at:

http://n.neurology.org/content/89/11/1152.full

Supplementary material can be found at:

http://n.neurology.org/content/suppl/2017/08/16/WNL.0000000000004 357.DC2

http://n.neurology.org/content/suppl/2017/08/16/WNL.0000000000004 357.DC1

http://n.neurology.org/content/suppl/2017/08/16/WNL.0000000000004 357.DC3

http://n.neurology.org/content/suppl/2017/09/11/WNL.0000000000004 357.DC4

This article cites 29 articles, 10 of which you can access for free at: http://n.neurology.org/content/89/11/1152.full\#ref-list-1

This article has been cited by 6 HighWire-hosted articles: http://n.neurology.org/content/89/11/1152.full\#\#otherarticles

This article, along with others on similar topics, appears in the following collection(s):

Clinical trials Randomized controlled (CONSORT agreement)

http://n.neurology.org/cgi/collection/clinical_trials_randomized_control led_consort_agreement

Parkinson's disease/Parkinsonism

http://n.neurology.org/cgi/collection/parkinsons_disease_parkinsonism

Information about reproducing this article in parts (figures,tables) or in its entirety can be found online at:

http://www.neurology.org/about/about_the_journal\#permissions

Information about ordering reprints can be found online:

http://n.neurology.org/subscribers/advertise

Neurology ${ }^{\circledR}$ is the official journal of the American Academy of Neurology. Published continuously since 1951, it is now a weekly with 48 issues per year. Copyright @ 2017 American Academy of Neurology. All rights reserved. Print ISSN: 0028-3878. Online ISSN: 1526-632X.

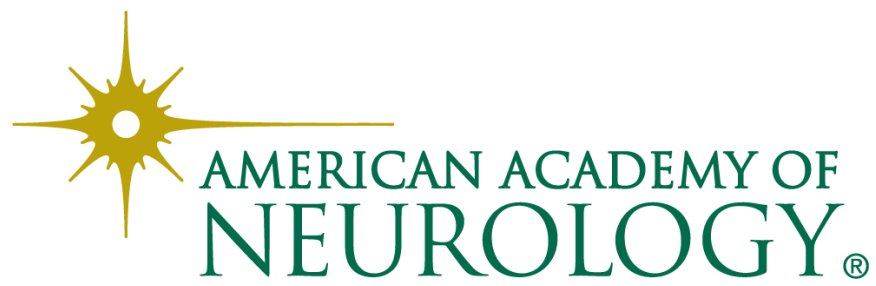

